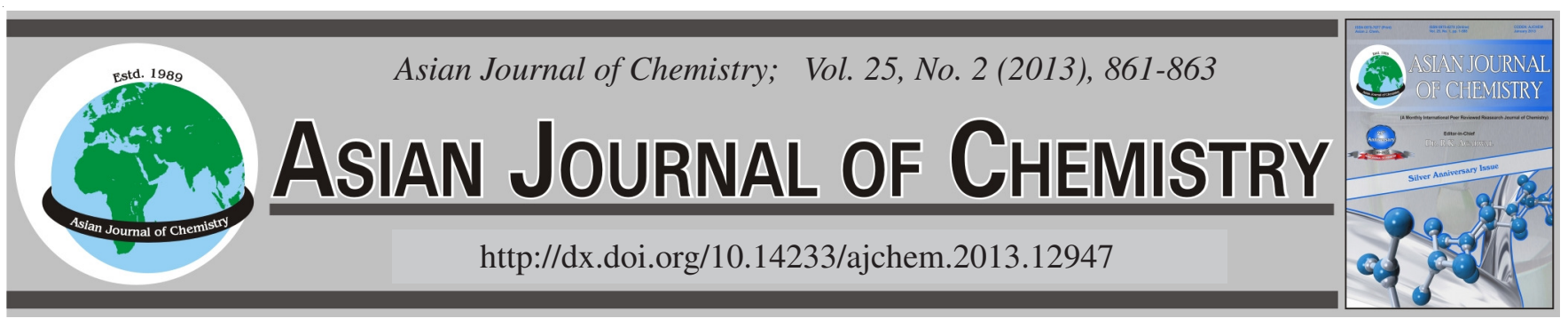

\title{
Detection of Heavy Metals Based on Boron-doped Diamond Nanograss Array, Boron-doped Diamond Film and Glassy Carbon Electrodes
}

\author{
Min WeI ${ }^{1, *}$, GAO YING ZENG ${ }^{1}$, Yong LiU ${ }^{2}$ and QIYU Lu' ${ }^{1}$
}

${ }^{1}$ College of Food Science and Technology, Henan University of Technology, Zhengzhou 450052, P.R. China

${ }^{2}$ College of Chemistry and Chemical Engineering, Henan University, Kaifeng 475004, P.R. China

*Corresponding author: E-mail: wei_min80@163.com

\begin{abstract}
In this work, boron-doped diamond nanograss array, boron-doped diamond film and GC electrode were used to investigate the voltammetric response of $\mathrm{Cd}^{2+}$ and determination of the mixture of $\mathrm{Cd}^{2+}, \mathrm{Pb}^{2+}$ and $\mathrm{Cu}^{2+}$ with differential pulse stripping voltammetry. For the stripping of $\mathrm{Cd}$, although GC electrode was slightly better than boron-doped diamond nanograss array and boron-doped diamond film electrode in terms of peak current response, the reproducibility of boron-doped diamond nanograss array electrode was superior to that of boron-doped diamond film and GC electrode. In case of determination of the mixture of $\mathrm{Cd}^{2+}, \mathrm{Pb}^{2+}$ and $\mathrm{Cu}^{2+}$, boron-doped diamond nanograss array electrode provided better analytical detection when compared to boron-doped diamond film and GC electrode. These results demonstrated that the boron-doped diamond nanograss array electrode was quite satisfactory with less surface adsorption, better reproducibility and higher resolution.
\end{abstract}

Key Words: Heavy metals, Boron-doped diamond nanograss array, Differential pulse stripping voltammety.

\section{INTRODUCTION}

Due to their tendency to accumulate in the body, toxicity and low rate of clearance, there existed health problems associated with exposure to high levels of metal ions such as $\mathrm{Cd}^{2+}$, $\mathrm{Pb}^{2+}, \mathrm{Hg}^{2+}$. Therefore, it is essential to detect toxic trace metals in the environment and aquatic food product for human health and safety.Currently, the recommended techniques for metal ion analysis are atomic absorption spectroscopy, atomic emission, inductively couple plasma mass spectrometry and anodic stripping voltammetry. Among these techniques, anodic stripping voltammetry has attracted a great deal of attention due to its advantages including wide linear dynamic range, low detection limit, multi element analysis capability, simplicity of the instrumentation, easy operational procedures and portability ${ }^{1,2}$.

The glassy carbon (GC) electrode is commonly considered to be the electrode material for anodic stripping voltammetry ${ }^{3}$ and numerous applications in trace metal analysis involve the mercury-coated GC electrode ${ }^{4,5}$ or polymer-covered GC electrode $e^{6,7}$.However, these types of electrodes pose some problems such as the inherent toxicity of the material, the introduction of discouraging environmental legislation ${ }^{5,8-9}$, film stability ${ }^{10,11}$ and preparation and deactivation of the electrode surface $^{12}$.

Because the boron-doped diamond (BDD) film electrode is free of above-mentioned problems ${ }^{13,14}$, it has become an attractive working electrode in anodic stripping voltammetry for the detection of toxic trace metal ions ${ }^{1-3,8}$. Although BDD film electrodes exhibit several advantages including wide potential window, low background current, long-term stability and excellent resistance to electrode fouling, they do have some inevitable drawbacks such as chemical inertness, unfavorable electrocatalytic activity, which may limit their applications. Therefore, surface modification of BDD film electrodes is necessary to improve their detection performance.

In our previous reports ${ }^{15,16}$, the BDD nanograss array was obtained and has been approved to improve reactive site, accelerate electron transfer, promote electrocatalytic activity and enhance selectivity by detecting different substances. In this work, BDD nanograss array electrode was used to investigate the voltammetric response of $\mathrm{Cd}^{2+}$ and determination of the mixture of $\mathrm{Cd}^{2+}, \mathrm{Pb}^{2+}$ and $\mathrm{Cu}^{2+}$ by differential pulse stripping voltammetry. It has been compared with BDD film and GC electrode in terms of sensitivity, reproducibility and resolution for the mixture.

EXPERIMENTAL
\[ \left(\mathrm{Cd}\left(\mathrm{NO}_{3}\right)_{2} \cdot 4 \mathrm{H}_{2} \mathrm{O}\right), \mathrm{Pb}\left(\mathrm{NO}_{3}\right)_{2}, \mathrm{Cu}\left(\mathrm{NO}_{3}\right)_{2} \cdot 3 \mathrm{H}_{2} \mathrm{O},\left(\mathrm{CH}_{3} \mathrm{COOH}\right), \]
$\left(\mathrm{CH}_{3} \mathrm{COONa}\right)$ were obtained from Shanghai chemical reagent
factory. All reagents were used as received without any further
treatment. Milli-Q water $(>18 \mathrm{M} \Omega \mathrm{cm})$ was used through-
out the experiments. The supporting electrolyte was acetate
buffer solution (pH 4.7) prepared with $\left(\mathrm{CH}_{3} \mathrm{COONa}\right)$ and
$\left(\mathrm{CH}_{3} \mathrm{COOH}\right)$.


Electrochemical measurements were performed with a CHI 660 electrochemical analyzer (CH Instruments, Chenhua Co. Shanghai, China) with a three electrode electrochemical cell. $\mathrm{An} \mathrm{Ag} / \mathrm{AgCl}$ (saturated $\mathrm{KCl}$ ) reference electrode and a $\mathrm{Pt}$ wire counter electrode were used.The BDD film and the BDD nanograss array electrodes were sonicated successively in 2-propanol and Milli-Q water before use. GC electrodes were polished with 0.10 and $0.05 \mathrm{~mm}$ alumina powder, respectively, rinsed thoroughly with Milli-Q water between each polishing step and then sonicated in acetone and Milli-Q water successively. The geometric areas of the working electrodes in the cell were estimated to be $0.07 \mathrm{~cm}^{2}$.

Preparation of the BDD film and the BDD nanograss array: The preparation of the BDD film and the BDD nanograss array was reported elsewhere ${ }^{15}$.

\section{RESULTS AND DISCUSSION}

Detection of $\mathrm{Cd}^{2+}$ on BDD nanograss array, BDD film and GC electrode: The voltammetric response of $\mathrm{Cd}^{2+}$ on BDD nanograss array, BDD film and GC electrode was investigated with differential pulse stripping voltammetry (DPSV). First, using a fixed concentration of $50 \mu \mathrm{M} \mathrm{Cd} d^{2+}$ in $0.1 \mathrm{M}$ acetate buffer solution ( $\mathrm{pH} 4.7$ ), different parameters such as pulse amplitude $\left(A_{p}\right)$, deposition potential $\left(E_{\text {dep }}\right)$, deposition time $\left(\mathrm{T}_{\mathrm{dep}}\right)$ were optimized to produce the best stripping signal on different electrodes and the results are shown in Table-1.

\begin{tabular}{lccc}
\multicolumn{4}{c}{ TABLE-1 } \\
\multicolumn{4}{c}{$\begin{array}{c}\text { OPTIMAL PARAMETERS FOR DPSV } \\
\text { ON DIFFERENT ELECTRODES }\end{array}$} \\
\hline \multicolumn{1}{c}{ Electrode } & $\mathrm{A}_{\mathrm{p}}(\mathrm{mV})$ & $\mathrm{E}_{\text {dep }} / \mathrm{V} v \boldsymbol{v} . \mathrm{Ag} / \mathrm{AgCl}$ & $\mathrm{T}_{\text {dep }}(\mathrm{s})$ \\
\hline BDD nanograss array & 50 & -1.10 & 60 \\
BDD film & 50 & -1.15 & 90 \\
$\mathrm{GC}$ & 50 & -1.40 & 60 \\
\hline
\end{tabular}

Using the experimental conditions described above, comparison of DPSV curves and reproducibility for the stripping of $\mathrm{Cd}$ was studied with different electrodes in $0.1 \mathrm{M}$ acetate buffer solution ( $\mathrm{pH} 4.7$ ) containing $50 \mu \mathrm{M} \mathrm{Cd}^{2+}$ and the results are shown in Fig.1 and Table-2. As seen in Fig. 1, for the stripping of $\mathrm{Cd}$, well-defined stripping peaks were observed on the three electrodes. The stripping peak potential for $\mathrm{Cd}^{2+}$ was similar on each electrode indicating that BDD is as active as GC for metal phase formation and oxidation. Due to the more heterogeneous chemical and electrical properties across the BDD film surface, the stripping peak was broader and more asymmetric than that for BDD nanograss array and GC electrode ${ }^{1}$. The peak current on the GC electrode was largest and then that on the BDD nanograss array electrode. In comparison with the BDD film electrode, the increase in peak current for the detection of $\mathrm{Cd}^{2+}$ on the BDD nanograss array electrode was ascribed to that the structure of nanograss array could increase the surface area, provide better electric linkage between electrode active sites, promote the electrocatalytic ability and accelerate the electron transfer ${ }^{15}$.

Table-2 shows comparison of eight-successive voltammetric responses of $50 \mu \mathrm{M} \mathrm{Cd}^{2+}$ on BDD nanograss array, BDD film and GC electrode. It can be seen that on the three

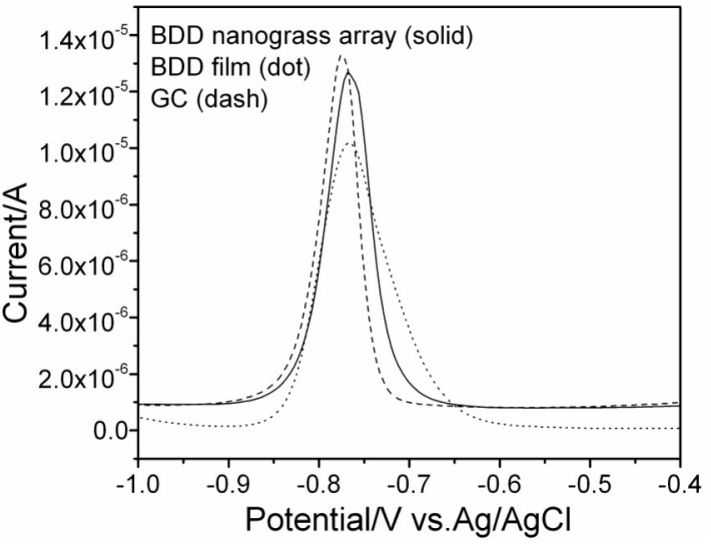

Fig. 1. DPSV curves for the stripping of $\mathrm{Cd}$ from $0.1 \mathrm{M}$ acetate buffer solution ( $\mathrm{pH} 4.7$ ) containing $50 \mu \mathrm{M} \mathrm{Cd}^{2+}$ on BDD nanograss array (solid line), BDD film (dot line) and GC (dash line) electrodes. Experimental conditions as in Table-1

\begin{tabular}{|c|c|c|c|}
\hline \multicolumn{4}{|c|}{$\begin{array}{c}\text { TABLE-2 } \\
\text { COMPARISON OF REPRODUCIBILITY FOR THE } \\
\text { STRIPPING OF CD ON DIFFERENT ELECTRODES }\end{array}$} \\
\hline Electrode & Number & Potential/V vs. Ag/AgCl & Current $\left(10^{-6} \mathrm{~A}\right)$ \\
\hline \multirow{9}{*}{$\begin{array}{l}\text { BDD } \\
\text { nanograss } \\
\text { array }\end{array}$} & 1 & -0.768 & 12 \\
\hline & 2 & -0.772 & 11.99 \\
\hline & 3 & -0.772 & 11.98 \\
\hline & 4 & -0.772 & 11.95 \\
\hline & 5 & -0.772 & 11.93 \\
\hline & 6 & -0.772 & 11.93 \\
\hline & 7 & -0.772 & 11.91 \\
\hline & 8 & -0.772 & 11.91 \\
\hline & $\operatorname{RSD}(\%)$ & - & 0.3001 \\
\hline \multirow{9}{*}{ BDD film } & 1 & -0.78 & 10.57 \\
\hline & 2 & -0.784 & 10.45 \\
\hline & 3 & -0.784 & 10.44 \\
\hline & 4 & -0.784 & 10.39 \\
\hline & 5 & -0.78 & 10.31 \\
\hline & 6 & -0.78 & 10.26 \\
\hline & 7 & -0.78 & 10.2 \\
\hline & 8 & -0.78 & 10.15 \\
\hline & RSD (\%) & - & 1.3678 \\
\hline \multirow{9}{*}{ GC } & 1 & -0.768 & 12.16 \\
\hline & 2 & -0.776 & 11.75 \\
\hline & 3 & -0.772 & 11.96 \\
\hline & 4 & -0.776 & 12.02 \\
\hline & 5 & -0.776 & 11.84 \\
\hline & 6 & -0.78 & 11.64 \\
\hline & 7 & -0.78 & 11.38 \\
\hline & 8 & -0.78 & 10.5 \\
\hline & $\operatorname{RSD}(\%)$ & - & 4.5099 \\
\hline
\end{tabular}

electrodes, the peak potentials changed and the peak currents dropped to varying degrees due to the fouling of the electrodes, which occurred as a result of the formation of a passive film by the continuous adsorption of the products. The peak potential shifted by $c a$. $0.004 \mathrm{~V}$ on BDD nanograss array and BDD film electrode whereas $c a .0 .012 \mathrm{~V}$ on the GC electrode. On BDD nanograss array electrode, the peak currents dropped from 12 $\times 10^{-6}-11.91 \times 10^{-6} \mathrm{~A}$ and the response reproducibility was $0.3001 \%$ (RSD). On BDD film electrode, the peak currents dropped from $10.57 \times 10^{-6}-10.15 \times 10^{-6} \mathrm{~A}$ and the response reproducibility was $1.3678 \%$ (RSD). On GC electrode, the peak currents changed from $12.16 \times 10^{-6}-10.5 \times 10^{-6} \mathrm{~A}$ and the response reproducibility was $4.5099 \%$ (RSD). These results 
demonstrated that BDD nanograss array electrode had favourable quality about low tendency for adsorption and was superior to BDD film and GC electrode.

Detection of the mixture of $\mathrm{Cd}^{2+}, \mathrm{Pb}^{2+}, \mathrm{Cu}^{2+}$ on BDD nanograss array, BDD film and GC electrode: Fig. 2 shows DPSV curves for determination of the mixture containing $\mathrm{Cd}^{2+}$, $\mathrm{Pb}^{2+}, \mathrm{Cu}^{2+}$ with concentration of 10 and $50 \mu \mathrm{M}$ in $0.1 \mathrm{M}$ acetate buffer solution ( $\mathrm{pH}$ 4.7) obtained on BDD nanograss array, BDD film and GC electrodes. It can be seen that BDD nanograss array electrode had the best ability toward the detection of $\mathrm{Cu}$ (ca. $-0.055 \mathrm{~V}$ versus $\mathrm{Ag} / \mathrm{AgCl})$ and then BDD film electrode. However, there was no characteristic peak of $\mathrm{Cu}$ observed on $\mathrm{GC}$ electrode. For the stripping of $\mathrm{Cd}$, the stripping peaks (ca. $-0.8 \mathrm{~V}$ versus $\mathrm{Ag} / \mathrm{AgCl}$ ) were welldefined with concentration of $50 \mu \mathrm{M}$ whereas ill-defined with concentration of $10 \mu \mathrm{M}$ on the three electrodes. The characteristic peak for the stripping of $\mathrm{Pb}$ became various at different concentrations: In the presence of $10 \mu \mathrm{M}$, there occurred single distinct stripping peak of $\mathrm{Pb}$ on BDD nanograss array electrode (ca. $-0.5 \mathrm{~V}$ versus $\mathrm{Ag} / \mathrm{AgCl}$ ) and $\mathrm{BDD}$ film electrode (ca. -0.55 $\mathrm{V}$ versus $\mathrm{Ag} / \mathrm{AgCl}$ ) whereas both a primary peak (ca. $-0.57 \mathrm{~V}$ versus $\mathrm{Ag} / \mathrm{AgCl}$ ) and a minor one (ca. $-0.47 \mathrm{~V}$ versus $\mathrm{Ag} / \mathrm{AgCl})$ on $\mathrm{GC}$ electrode. In the presence of $50 \mu \mathrm{M}$, there are both a primary peak and a minor one observed in the potential range from $-0.6 \mathrm{~V}$ to $-0.4 \mathrm{~V}$ on the three electrodes. The formation of double peaks may have to do with the inactivity of electrode surface. From the above results, it can be concluded that BDD nanograss array was a more efficient electrode material towards the detection of the mixture with less surface adsorption and higher resolution.
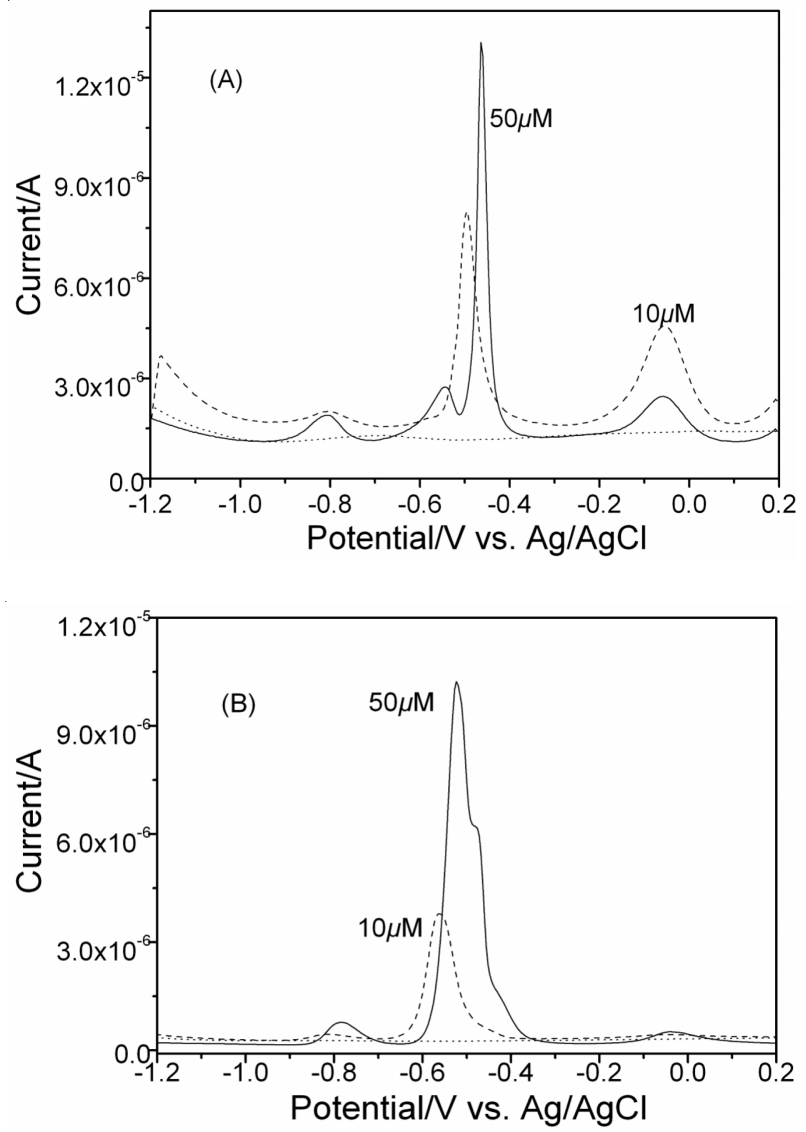

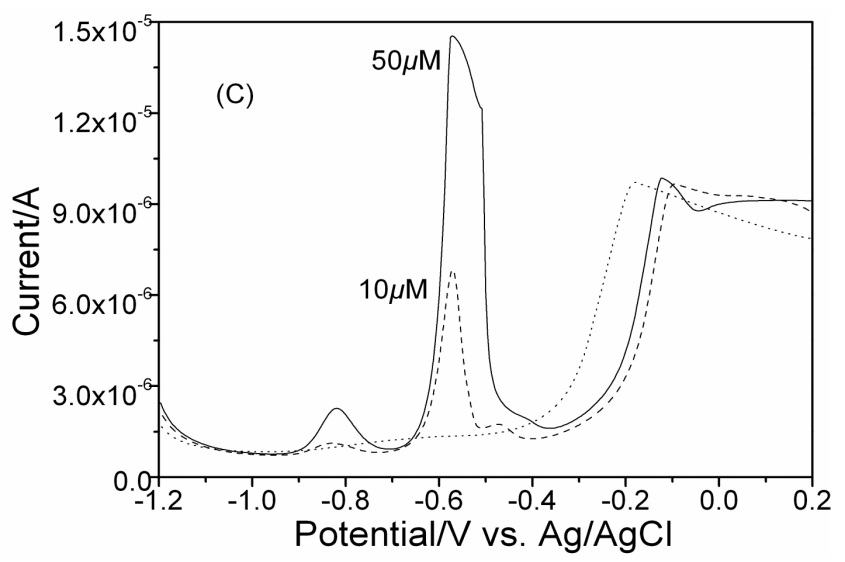

Fig. 2. DPSV curves for a mixture containing $\mathrm{Cd}^{2+}, \mathrm{Pb}^{2+}, \mathrm{Cu}^{2+}$ with concentration of $0 \mu \mathrm{M}$ (dot line), $10 \mu \mathrm{M}$ (dash line) and $50 \mu \mathrm{M}$ (solid line) in $0.1 \mathrm{M}$ acetate buffer solution ( $\mathrm{pH} 4.7$ ) obtained on (A) BDD nanograss array, (B) BDD film and (C) GC electrodes

\section{Conclusion}

Electrochemical technique is significant for the determination of heavy metals. The choice of working electrode is important. The results of this work demonstrated that, as a novel electrode material, the BDD nanograss array was more efficient towards the detection of heavy metal with less surface adsorption, better reproducibility and higher resolution.

\section{ACKNOWLEDGEMENTS}

This research was supported by National Natural Science Foundation of China (Grant No. 21105022) and Doctor Foundation of Henan University of Technology (2010BS019).

\section{REFERENCES}

1. E.A. McGaw and G.M. Swain, Anal. Chim. Acta, 575, 180 (2006).

2. A. Manivannan, R. Kawasaki, D.A. Tryk and A. Fujishima, Electrochim. Acta, 49, 3313 (2004).

3. C. Babyak and R.B. Smart, Electroanalysis, 16, 175 (2004).

4. K.Z. Brainina, N.A. Malakhova and N.Y. Stojko, J. Anal. Chem., 368, 307 (2000)

5. C. Agra-Gutierrez, J.L. Hardcastle, J.C. Ball and R.G. Compton, Analyst, 124, 1053 (1999).

6. I. Turyan, M. Atiya and D. Mandler, Electroanalysis, 13, 653 (2001).

7. K.C. Honeychurch, J.P. Hart and D.C. Cowell, Anal. Chim. Acta, 431, 89 (2006).

8. C.E. Banks, M.E. Hyde, P. Tomcik, R. Jacobs and R.G. Compton, Talanta, 62, 279 (2004).

9. E. Gustafsson, Water, Air Soil Pollut., 80, 99 (1995).

10. S.C. Petrovic and H.D. Dewald, Anal. Chim. Acta, 357, 33 (1997).

11. H.P. Wu, Anal. Chem., 66, 3151 (1994).

12. In Interfacial Electrochemistry: Theory, Experiment and Applications, R.L. McCreery, Marcel Decker, New York (1999).

13. J. Xu, M.C. Granger, Q. Chen, J.W. Strojek, T.E. Lister and G.M. Swain, Anal. Chem., 69, A591 (1997).

14. J. Xu, Q. Chen and G.M. Swain, Anal. Chem., 70, 3146 (1998).

15. M. Wei, C. Terashima, M. Lv, A. Fujishima and Z.Z. Gu, Chem. Commun., 24, 3624 (2009).

16. M. Lv, M. Wei, F. Rong, C. Terashima, A. Fujishima and Z.Z. Gu, Electroanalysis, 22, 199 (2010). 